Ciência Florestal, Santa Maria, v. 23, n. 3, p. 507-516, jul.-set., 2013

ISSN 0103-9954

\title{
O USO DE ÁGUA PELAS PLANTAÇÕES FLORESTAIS - UMA REVISÃO
}

\author{
THE WATER USE BY FOREST PLANTATIONS - A REVIEW
}

Silvana Lucia Caldato ${ }^{1}$ Mauro Valdir Schumacher ${ }^{2}$

\begin{abstract}
RESUMO
O objetivo desta revisão bibliográfica é apresentar alguns dos principais resultados e inferir sobre o estado de arte atual sobre o controvertido tema do uso de água pelas plantações florestais. Inúmeros trabalhos têm sido realizados nesta área em diferentes regiões, principalmente Austrália, África do Sul, Europa, Índia e Brasil. No entanto, segundo os pesquisadores, a polêmica persiste e é necessária a divulgação dos estudos científicos à comunidade para que os mitos sejam confrontados com a ciência. Portanto, esta revisão busca sintetizar resultados científicos sobre os principais aspectos hidrológicos das plantações (interceptação, transpiração e balanço hídrico), a relação entre a alta produtividade e a eficiência do uso da água e a importância do manejo florestal, visando contribuir para a sustentabilidade hidrológica. Por esta revisão, ficou claro que a relação entre as plantações florestais e a água depende da espécie, das condições ambientais e das práticas de manejo em escala regional tendo como foco a microbacia hidrográfica.
\end{abstract}

Palavras-chave: Eucalyptus; Pinus; recursos hídricos; microbacias.

\begin{abstract}
This review aims to present some of the main results and infer about the current state-of-the-art of the controversy related to the water use by forest plantations. Several studies have been carried out in this area in different regions, mainly in Australia, South Africa, Europe, India and Brazil. However, according to authors, the controversy persists and it is necessary that the scientific results are understood by the community in order to avoid the predominance of myths and half-truths. In this way, the current review intends to summarize some scientific results concerning the main hydrologic aspects of the plantations (interception, transpiration and catchment water balance), the relationship between the high productivity and the water use efficiency, and the importance of the establishment of forest management plan focused on the river watershed scale, in order to contribute to hydrological sustainability. The results coincide that the relationship between the forest plantations and the water depends on the region, species, environmental conditions and management practices on the watershed scale.
\end{abstract}

Keywords: Eucalyptus; Pinus; water resources; watersheds.

\section{INTRODUÇÃO}

O uso de água pelas plantações florestais tem, historicamente, criado muitas controvérsias em diversas partes do mundo (LIMA, 2006; ALMEIDA et al., 2007; CALDER et al., 2007; KALLARACKAL e SOMEN, 1997; HAMILTON, 2008). A sociedade humana está preocupada sobre os impactos positivos e negativos da floresta referentes à quantidade de água, não só quando há muita água (enchentes) e às vezes quando não há o suficiente (estiagens). Esta preocupação envolve muitos mitos e muitas interpretações e informações precárias (HAMILTON, 2008).

Para Wilk (2000), a utilização da água deve ser vista no contexto de um ciclo, onde a água absorvida pelas árvores na transpiração retorna novamente à superfície pela precipitação. No entanto, um apropriado manejo da água é um ponto crucial, visando garantir tanto o uso equitativo quanto qualitativo por todos os usuários.

1 Engenheira Florestal, Doutoranda do Programa de Pós-graduação em Engenharia Florestal, Centro de Ciências Rurais, Universidade Federal de Santa Maria, CEP 97105-900, Santa Maria (RS). Bolsista CNPq. scaldato@yahoo.com.br

2 Engenheiro Florestal, Dr., Professor Associado do Departamento de Ciências Florestais, Centro de Ciências Rurais, Universidade Federal de Santa Maria, CEP 97105-900, Santa Maria (RS). Bolsista CNPq. schumacher@pq.cnpq.br Recebido para publicação em 29/07/2009 e aceito em 19/10/2011 
De acordo com Mendes e Lima (2007), a falta de clareza nas relações causais, que integram vários usos de água em bacias hidrográficas, faz com que vários conflitos de usos sejam atribuídos às plantações florestais. Por exemplo, segundo Dye e Versfeld (2007), a África do Sul possui poucos recursos florestais naturais e, desta forma, depende das plantações com espécies exóticas para suprir suas necessidades de madeira. As plantações cobrem 1,2\% da área total da África do Sul e usam 3\% da disponibilidade nacional de água deste país. No entanto, por causa da polêmica, a atividade florestal está sendo intimada a pagar pela água consumida pelas plantações florestais. Para Hamilton (2008), uma razão porque outros cultivos (milho, trigo, sorgo e cana-de-açúcar) não terem sido classificados como redutores da vazão é a ausência de dados sobre o consumo de água por essas culturas.

Segundo Calder et al. (2007), apesar dos significativos progressos na compreensão científica das interações entre as florestas e a água, a função desempenhada pelos plantios florestais em relação ao manejo sustentável dos recursos hídricos continua sendo um assunto não resolvido. Persistem as dificuldades ao tentar transferir os resultados das pesquisas a diferentes países e regiões, bacias hidrográficas com diferentes dimensões, tipo de florestas, espécies e regimes diferenciados de manejo florestal. Para os autores, outra dificuldade reside na distância entre a pesquisa e a política. Esta distância não tem sido superada, devido, entre outras coisas, às dificuldades de se transmitirem eficazmente os resultados das pesquisas científicas.

Estudos têm mostrado que a relação entre as plantações florestais e a água depende da região, espécie, condições ambientais, práticas do uso do solo na escala da microbacia hidrográfica (ALMEIDA e SOARES, 2003; ANDRÉASSIAN, 2004; BROWN et al., 2005; VAN DIJK e KEENAN, 2007).

Entre os trabalhos mais recentes de revisão sobre as plantações florestais e a água (ANDRÉASSIAN, 2004; WHITEHEAD eBEADLE, 2004; BROWN et al., 2005; FARLEY et al., 2005; DYE e VERSFELD, 2007; VAN DIJK e KEENAN, 2007; VANCLAY, 2009), a conclusão geral é que o uso de água pelas plantações depende das condições do sítio, clima, espécies e principalmente das práticas de manejo. Pode-se até afirmar, desta maneira, que o surgimento de algum eventual conflito devido ao consumo da água pelas plantações florestais é o resultado de estratégia inadequada de manejo, tanto no sentido de não se analisar previamente as condições de disponibilidade natural de água da região, quanto de não se levar em conta os valores da água em sua implementação.

Portanto, esta revisão busca sintetizar os resultados mais importantes publicados sobre o uso de água e as plantações florestais.

\section{ASPECTOS HIDROLÓGICOS DO USO DA ÁGUA POR PLANTAÇÕES FLORESTAIS}

O uso de água pelas plantas pode ser definido, de acordo com Benyon et al. (2007), como a perda total evaporativa, que resulta da interceptação, evaporação do solo e da transpiração, também conhecida normalmente como evapotranspiração. Aproximadamente, dois terços da precipitação global retornam para atmosfera em forma de evaporação, constituindo-se o principal componente do ciclo hidrológico (WALLACE, 1995). O uso da água pelas plantas ou transpiração (movimento da água através do sistema solo-planta-atmosfera) é o mecanismo mais importante de transferência da água do solo para a atmosfera quando o solo está coberto pela vegetação (CARLESSO e ZIMMERMMANN, 2000). Aproximadamente, $95 \%$ da água absorvida pelas raízes é liberada para a atmosfera pela planta como vapor de água (PALLARDY, 2008).

\section{Interceptação}

O efeito hidrológico mais importante causado pelas plantações em seu âmbito local é a interceptação da precipitação, a qual se pode considerar como uma fração da água da chuva que retorna à atmosfera sem atingir o solo (LIMA, 1993; CECCON e MARTINEZ-RAMOS, 1999). Do total da precipitação em um ecossistema florestal, uma porção é interceptada pelo dossel, outra tem o fluxo pelo tronco ou pelo gotejamento das folhas e galhos, como também pode passar pelos espaços abertos do dossel ou ser interceptada pela serapilheira no piso florestal (CHANG, 2006).

Nos trópicos, a interceptação é um componente significativo da evaporação anual da floresta. As florestas tropicais úmidas podem converter, numa base anual, o equivalente a praticamente toda a radiação líquida em evaporação. É improvável que qualquer outro uso da terra evaporará a uma velocidade mais alta. Portanto, a conversão da floresta em cultivos anuais nestas áreas, assim como na maioria de outras áreas do mundo, provavelmente resultará em maiores fluxos anuais dos cursos de água (CALDER, 1998). 
A proporção da chuva interceptada depende principalmente das características da floresta e regimes das chuvas, variando consideravelmente entre espécies. De acordo com Zhang et al. (1999), em média, uma floresta de pinus intercepta $28 \%$ da precipitação comparada com $14 \%$ para floresta de eucalipto. Perdas por interceptação em estudos com eucalipto na Austrália, Índia e Israel variam de 10 a 34\% da precipitação anual (CALDER, 1986; WHITEHEAD e BEADLE, 2004). No Brasil, a perda média por interceptação para Eucalyptus grandis com 9 anos de idade foi de $11 \%$ da precipitação anual, sendo as perdas maiores em períodos secos, quando as chuvas são menos intensas (SOARES e ALMEIDA, 2001).

Portanto, as diferenças fisionômicas e estruturais do dossel podem ter influência na interceptação da chuva e desta forma sobre o balanço hídrico. Perdas por interceptação são geralmente menores para florestas de folhosas do que para florestas de coníferas; sendo que características como menor albedo e maior rugosidade do dossel das florestas de coníferas comparadas com florestas de latifoliadas, podem explicar esta diferença, pois as coníferas tendem a absorver mais energia (BENYON et al., 2007). Tais diferenças na interceptação da precipitação podem ser ou não compensadas pelas diferenças da evaporação do solo, da transpiração (VAN DIJK e KEENAN, 2007) e da infiltração. Li et al. (2008), estudando o fluxo de água pelo tronco de arbustos na região semiárida na China, verificaram que este pode ser canalizado para níveis mais profundos no solo com arbustos que em sítios sem arbustos, criando condições favoráveis de água no solo para o crescimento das plantas nos ambientes com estresse hídrico.

\section{Transpiração}

A transpiração nas plantas vasculares ocorre principalmente por meio dos microscópicos poros nas superfícies das folhas, conhecidos como estômatos, sendo a regulação da abertura estomática o principal mecanismo que controla as taxas de transpiração (LARCHER, 2006). Segundo Vincke e Thiry (2008), a vegetação arbórea, devido à sua longevidade e à sua alta capacidade evaporativa, tem uma grande influência no ciclo hídrico; podendo transpirar $80 \%$ da evapotranspiração potencial sob alta demanda evaporativa. Assim, a demanda evaporativa da atmosfera, que compreende condições climáticas como radiação, déficit de pressão de sa- turação do ar, umidade relativa, velocidade do vento e temperatura; e fatores como condutância e estrutura do dossel, índice de área foliar e disponibilidade de água no solo, determinam as perdas de água por transpiração (CANNELL, 1999).

Consequentemente, a taxa de transpiração das plantações florestais varia basicamente em função da localização geográfica, condições ambientais e das espécies plantadas. No Chile, Huber e Trecaman (2004), estudando a eficiência do uso de água em plantações de Pinus radiata, observaram que as menores taxas de transpiração estiveram associadas a solos com boa capacidade de retenção de água, eventos importantes de chuva e menor quantidade de vegetação competidora. Já Vincke e Thiry (2008), estudando a evapotranspiração e o conteúdo de água no solo em plantio de Pinus sylvestris na Bélgica, encontraram que a máxima transpiração da espécie foi limitada pelo seu índice de área foliar (IAF).

No Brasil, Soares e Almeida (2001) concluíram, para plantações na Costa Atlântica com Eucalyptus grandis, que houve um déficit de transpiração em torno de $125 \mathrm{~mm}$, causado pela concentração da precipitação durante a primavera e o verão, e um período seco mais longo no outono e no inverno; o fluxo ascendente da água da zona abaixo das raízes ajudou a evitar o fechamento dos estômatos e manteve a plantação de eucalipto com, aproximadamente, $30 \%$ de seu potencial no final da estação seca. Neste caso, pode-se observar que a transpiração diminui significativamente com o aumento do déficit de água no solo. Para esta mesma região, Mielke et al. (1999) mostram que as trocas de vapor de água das plantações com Eucalyptus grandis são fortemente dominadas pelo déficit regional de vapor de pressão e que a transpiração do dossel é controlada principalmente pela condutância estomática.

Em termos de comparação da evapotranspiração entre ecossistemas distintos, estudos demonstram que os resultados variam em função das condições ambientais. Por exemplo, McJannet et al. (2000) na Austrália, compararam medições de evapotranspiração em plantações florestais e pastagens. Na primavera, a evapotranspiração da pastagem foi $65 \%$ da observada na plantação; no verão, a evapotranspiração da pastagem foi somente $35 \%$ à da plantação. Durante o período de verão seco, a transpiração diária da plantação foi somente $20 \%$ da medida durante a primavera, sugerindo que a floresta não usa suprimento de água do lençol freático, mas 
busca o suprimento na água do solo. Já no Brasil, Almeida e Soares (2003) em estudo comparativo entre o uso de água em plantações de Eucalyptus grandis e Floresta Ombrófila Densa, concluíram que o eucalipto exerce controle estomático eficiente sobre a transpiração durante a estação seca e que o uso de água no solo e a evapotranspiração nas plantações se comparam à da Mata Atlântica.

Além da espécie, outro fator importante que influencia a taxa de transpiração é a idade do povoamento. Na Austrália, autores como Roberts et al. (2001) e Vertessy et al. (2001) descrevem uma relação positiva entre a idade de plantações de eucaliptos e a produção de água, havendo uma diminuição da transpiração e da interceptação com o aumento da idade, provavelmente, a transpiração alcança um pico por um período e então declina com a idade. Para Roberts et al. (2001), esta é uma evidência de que há um incremento na produção de água para este tipo de floresta com o aumento da idade. No Brasil, Almeida et al. (2007) estudaram o balanço hídrico em plantações de Eucalyptus grandis e relatam que a transpiração máxima anual $\left(>1000 \mathrm{~mm}^{2} \mathrm{ano}^{-1}\right)$ foi observada quando as plantações tinham 3344 meses de idade e 57-68 meses, com precipitação de $1272 \mathrm{~mm}$ e $1507 \mathrm{~mm}$, respectivamente. A precipitação média histórica é de $1350 \mathrm{~mm}$, a qual parece ser suficiente para satisfazer a demanda de água das plantações neste ambiente. Variações interanuais na precipitação e no índice de área foliar foram os principais determinantes do uso de água.

Finalmente, de acordo com Benyon e Doody (2004), quando o dossel se estabelece em cada rotação, o uso de água aumentará a um máximo, quando o índice de área foliar também estiver no máximo. Em plantações com acesso à água do lençol freático, o índice de área foliar máximo e uso de água ocorrem provavelmente quando a profundidade das raízes tenha alcançado a franja de capilaridade acima do lençol freático, o que pode não ocorrer por muitos anos após o plantio das árvores. Uma vez que as taxas de pico para o uso anual da água tenham sido alcançadas, estas, provavelmente, manter-se-ão por um tempo ao longo da rotação.

\section{Balanço hídrico de Microbacias}

As microbacias hidrográficas possuem um papel fundamental na ecologia dos ecossistemas e bem-estar da sociedade humana, sua importância incide principalmente no fornecimento de água doce de elevada qualidade, na regulação dos caudais e do escoamento superficial (CALDER et al., 2007). O balanço hídrico definido como a diferença entre a entrada de água pela precipitação e a perda pela evapotranspiração (CÂMARA et al., 2006) é indicador chave para avaliar o equilíbrio hidrológico da microbacia. Uma característica importante deste equilíbrio na maioria dos ambientes com estresse hídrico é que praticamente toda a chuva é evaporada ou transpirada e a drenagem é escassa (ELLIS et al., 2005).

Evidências atuais sugerem que as plantações florestais reduzem a disponibilidade de água, bem como baixam os níveis dos fluxos superficiais em microbacias pequenas, mas não são esperadas influências em microbacias grandes (VAN DIJK et al., 2007). Cabe ressaltar que, do ponto de vista hidrológico, as bacias hidrográficas são classificadas em grandes e pequenas, não com base em sua superfície total, mas nos efeitos de certos fatores dominantes na geração do deflúvio (LIMA e ZAKIA, 2004). Neste sentido, Keenan et al. (2006) afirmam que a conversão de terras com agricultura por plantações pode reduzir o escoamento e o fluxo superficial anual. Se isto ocorrer ao longo de uma proporção muito grande da bacia hidrográfica as consequências podem ser significativas no suprimento de água para outros usos. Também para Calder (2007), o uso de água nas florestas é geralmente maior do que o de outros cultivos não irrigados, levando a reduzir o fluxo anual das microbacias. A resposta hidrológica da microbacia às plantações florestais vai depender, portanto, da escala da microbacia coberta pelos plantios que varia em função da idade e da espécie. Quando se observa os indicadores hidrológicos considerando a escala, as respostas são distintas. Para Brown et al. (2007), estimando os impactos das plantações sobre a água em uma microbacia na Austrália, concluem que numa base média anual na escala da bacia total, os impactos de diferentes cenários de vegetação no fluxo superficial são mínimos. Entretanto, quando se consideram respostas locais, anos críticos e consecutivos alguns impactos potencialmente maiores são identificados. Na escala local, os resultados mostram um potencial de redução dos fluxos superficiais devido ao aumento da cobertura florestal na bacia de $37 \%$ para $71 \%$ da área.

Uma análise conjunta de 504 microbacias em diversas partes do mundo, realizada por Jackson et al. (2005), relata que, em 52\% dos casos, as plantações diminuíram o fluxo em média $227 \mathrm{~mm} \mathrm{ano}^{-1}$ e $13 \%$ dos cursos de água secaram 
completamente pelo menos um ano. Igualmente para Lima et al. (2008), os resultados obtidos nas microbacias experimentais do PROMAB (Programa de Monitoramento Ambiental em Microbacias) em São Paulo, mostram que, numa microbacia de 7,5 hectares, a diminuição gradativa do deflúvio anual chegou ao ponto de secar o riacho por ocasião da idade de colheita da plantação, tendo a vazão retornada após o corte. Nas microbacias com áreas maiores e localizadas em regiões caracterizadas climaticamente por disponibilidade suficiente de água, os resultados indicam também alguma diminuição no deflúvio em função do crescimento das plantações, sem chegar a secar completamente a vazão. Também em São Paulo, Câmara e Lima (1999), estudando os impactos do corte raso de uma plantação de Eucalyptus saligna de 50 anos de idade sobre o balanço hídrico de uma microbacia, verificaram baixos incrementos no deflúvio após o corte raso, o que reflete uma condição de equilíbrio entre a antiga cobertura florestal e o regime climático local.

A hidrologia florestal em uma microbacia também pode ser vista sob outros aspectos, como, por exemplo, de regularização do sistema. De acordo com Hamilton (2008), o aumento da disponibilidade de água com o corte da floresta parece desejável para o deflúvio, em curto prazo, na estação seca, mas pode ser um problema durante a estação úmida, quando o aumento do fluxo pode trazer risco de inundações. Também para Van Dijk e Keenan (2007), em alguns casos, as plantações podem aumentar a recarga do lençol freático por melhorar a infiltração.

\section{PRODUTIVIDADE DAS PLANTAÇÕES E A EFICIÊNCIA DO USO DA ÁGUA}

As plantas usam a água em quantidades variáveis, sendo influenciadas por um grande número de fatores, dentre eles, as condições climáticas, os tipos de solo e a taxa de crescimento. Para Cannell (1999), diferenças na transpiração entre tipos de florestas, estão, geralmente, relacionadas positivamente com a produção em volume, ou seja, para condições climáticas e nutricionais comparáveis, quanto mais água for transpirada maior será a taxa de crescimento das árvores. Segundo Whitehead e Beadle (2004), existe uma produtividade potencial alta para um grande número de espécies, o que resulta de altos valores de índice de área foliar, condutância estomática, e taxa fotossintética, em condições onde a água e nutrientes estão rapidamente disponíveis.
Em contraste, em sítios onde o suprimento de água e nutrientes é limitado ou temperaturas extremas são registradas, a produtividade é menor do que a potencial.

O trabalho de Stape et al. (2004) oferece um melhor entendimento da relação entre água e produtividade. Os autores, estudando a produção do eucalipto num gradiente regional no Brasil, encontraram que a precipitação $\left(\mathrm{mm} \mathrm{ano}^{-1}\right)$ foi a variável ambiental mais fortemente relacionada com o incremento médio anual (IMA- $\mathrm{Mg} \mathrm{ha}^{-1} \mathrm{ano}^{-1}$ ) e a produção de biomassa acima do solo (produção primária líquida - PPL- Mg ha ${ }^{-1}$ ano $^{-1}$ ), indicando que o suprimento de água é provavelmente a fonte primária que controla a produtividade em regiões tropicais. Por exemplo, para cada $100 \mathrm{~mm}$ por ano no incremento da precipitação, a produtividade aumentou $2,3 \mathrm{Mg} \mathrm{ha}^{-1} \mathrm{ano}^{-1}$. Os talhões mais produtivos usaram mais água ( $\left.869 \mathrm{~mm}^{2} \mathrm{ano}^{-1}\right)$, mas também foram os mais eficientes no uso deste recurso $(3,21 \mathrm{~kg}$ de PPL por $\mathrm{m}^{3}$ da água transpirada). $\mathrm{O}$ aumento da precipitação indiretamente também aumenta a eficiência do uso da luz e nitrogênio por aumentar sua eficácia na captura. Outros estudos realizados no Brasil por Almeida et al. (2004) e na África do Sul por Dye (1996), mostram que a precipitação e o déficit de vapor de pressão podem reduzir o crescimento das plantações de eucalipto; a distribuição da precipitação afeta a disponibilidade de água no solo e o déficit de vapor de pressão pode restringir o crescimento por seus efeitos sobre os estômatos.

Teorias eco-hidrológicas e evidências experimentais sugerem uma estreita relação entre a precipitação e o índice de área foliar, e cedo ou tarde as plantações alcançam uma área foliar e uso de água que estão em equilíbrio dinâmico com a disponibilidade de água e é independente do número inicial de árvores ou desbastes (HATTON et al., 1998; MCJANNET e VERTESSY, 2001; ELLIS et al., 2005). Neste sentido, Almeida et al. (2007) verificaram que o crescimento do eucalipto foi afetado pela idade do talhão, o que é influenciado pelo IAF e água disponível. O declínio no IAF com o aumento da idade, explica, em parte, a redução do uso de água pelas árvores no final da rotação comparada com a dos 3-4 anos.

O déficit hídrico do solo afeta o uso de água, pois as árvores usam a água preferencialmente na camada superior (até 1 metro) do solo, onde estão concentradas as raízes finas responsáveis principais pela absorção da água. Jarosz et al. (2008), avaliando a resposta de uma plantação de Pinus pinaster à 
seca na França, concluem que a eficiência do uso de água aumenta no verão com o aumento do déficit de água no solo e decresce com o aumento do déficit do vapor de pressão. O dossel de árvores de pinus usa a água mais eficientemente do que o subdossel, cuja contribuição para o uso eficiente de água de todo o ecossistema é baixo. Portanto, as plantas pelo controle estomático usam a água de maneira mais eficiente quando a disponibilidade é menor, sistema adotado por outras espécies, inclusive a humana.

Dados da eficiência no uso de água, publicados na Europa por Schrelzenmayr et al. (1981), mostram que para a produção de 1 grama de biomassa Pinus silvestre usa $344 \mathrm{~g}$ de água, Picea abies necessita 300 g e Fagus silvatica 169 g de água. No Brasil, Lima et al. (1990) e Lima (1993) descrevem que a eficiência do uso de água em plantações de Eucalyptus grandis, Pinus caribaea var. hondurensis e vegetação do cerrado, em gramas de madeira por quilo de água consumida foi de 2,9, 2,1 e 0,4 , respectivamente. De acordo com os autores, desconsiderando as perdas por interceptação, a plantação de eucalipto usou aproximadamente $215 \mathrm{~mm}$ de água a mais por ano que a vegetação natural de savana. De acordo com Whitehead e Beadle (2004), os altos valores da taxa (massa - área) e conteúdo de nitrogênio para populações de eucaliptos de sítios áridos sugerem que a alta eficiente no uso de água é atribuída principalmente pela alta capacidade fotossintética.

\section{O MANEJO DO USO DA ÁGUA PELAS PLANTAÇÕES FLORESTAIS}

Para Vanclay (2009), muitos fatores têm o potencial de afetar o uso de água pela plantação e poucas destas alternativas têm sido examinadas em detalhe. $\mathrm{O}$ autor ressalta a possibilidade de planificar e manejar as plantações florestais visando ao uso eficiente da água.

A importância de um manejo florestal adequado para proteger os recursos hídricos também é ressaltada por Farley et al. (2005). Para os autores, a grande maioria dos resultados de estudos em diversas partes do mundo, particularmente aqueles com plantações florestais, comparados com outros usos da terra bem manejados, indicam impactos neutrais a negativos.

Por outro lado, Bruijnzeel (2004) destaca que a infiltração pode ser mantida com o estabelecimento de um sistema de estradas planificado e conservado, e com o cuidado no momento da colheita.
A capacidade de infiltração constitui uma variável chave das características físicas do solo, que influencia a recarga do lençol freático e a perda potencial do solo superficial pela erosão (ILSTEDT et al., 2007). Segundo os autores, a infiltração aumenta em média três vezes mais depois do plantio de árvores em campos agrícolas. Também Zimmermann et al. (2006) verificaram maior infiltração em condições de uso do solo com floresta e menor em pastagem; destacando um considerável efeito residual (história do uso e manejo) nas propriedades hidráulicas do solo.

A localização, o desenho espacial das árvores plantadas e a aplicação de desbastes e podas (que diminuem a área foliar) também são opções de manejo que influenciam o uso de água. Estabelecer as plantações longe de cursos de água e linhas de drenagem já é uma prática comum em muitos países (embora por outras razões) e pode reduzir o impacto das árvores nos recursos hídricos (VAN DIJK e KEENAN, 2007). Em estudo realizado por Kallarackal e Somen (1997) na região tropical úmida da Índia, o uso de água por Eucalyptus tereticornis foi comparado em dois sítios com duas densidades (1800 árvores ha ${ }^{-1}$ e 1090 árvores ha ${ }^{-1}$ ), foram observadas características diferentes no uso de água pela espécie nos dois sítios com distintas condições climáticas e silviculturais, sendo o menor uso de água em plantações com menor densidade. Igualmente, Licata et al. (2008) obtiveram maior transpiração em povoamentos de Pinus ponderosa com maior densidade comparada com outras densidades e floresta nativa, na região noroeste da patagônia Argentina. De acordo aos autores, há um grande potencial para reduzir o consumo de água pelas plantações com o manejo da densidade dos talhões. O conhecimento das relações hídricas auxilia na definição de espaçamentos mais adequados para as espécies florestais, visando à melhor utilização desses fatores, de modo a aumentar a eficiência produtiva das plantas (LELES et al., 1998).

Fatores determinantes dos impactos das plantações sobre a segurança dos recursos hídricos são indicados por Van Dijk e Keenan (2007), que incluem: i) características do plantio que afetam a hidrologia florestal (diferenças na fisiologia das árvores, desenho e manejo das plantações, operações florestais); ii) o ponto de referência (uso atual com agricultura ou vegetação nativa) contra o que as mudanças são avaliadas, e; iii) a configuração do sistema hídrico (escala dos plantios, impactos temporais, localização e perdas internas). Estas considerações 
destacam a importância de se conhecer o contexto no qual as plantações estão inseridas e de se adotar boas práticas de manejo florestal.

\section{SÍNTESES}

$\mathrm{Na}$ compilação de resultados de estudos de microbacias, destacam-se a seguir as principais conclusões apresentadas pelos investigadores:

Para Andréassian (2004), sem dúvida as plantações possuem um impacto sobre o balanço hídrico na escala de bacias hidrográficas, sendo o consumo de água nas plantações geralmente maior que outro tipo de vegetação. $\mathrm{O}$ corte das árvores resulta num aumento da produção de água e o estabelecimento de plantios diminui. No entanto, não se sabe completamente as consequências com a idade do povoamento, ou com o aumento da porcentagem de cobertura florestal na escala da bacia hidrográfica. Também de acordo Bruijnzeel (2004), maior atenção deveria ser dada à base geológica que controla o comportamento hidrológico da microbacia quando se analisam os efeitos das mudanças do uso do solo sobre os fluxos superficiais ou a produção de sedimentos.

Já para Brown et al. (2005), as revisões prévias de estudos de microbacias pareadas dirigiram a atenção principalmente em experimentos de restabelecimento das plantações, em tais estudos, as mudanças na produção de água são observadas somente nos primeiros anos que seguem o tratamento e retornam aos níveis pré-tratamento. Uma comparação de resultados a longo prazo de experimentos de regeneração, de corte raso e de estabelecimento, indicam que mudanças permanentes na vegetação levam mais de 5 anos para a bacia alcançar um novo equilíbrio.

Também Van Dijk e Keenan (2007), na revisão dos impactos das plantações em terras agrícolas sobre os recursos hídricos, destacam que as plantações geralmente reduzem o fluxo médio dos cursos de água e a recarga do lençol freático, mas a um grau que depende da hidrologia atual da paisagem e das características das espécies arbóreas; frequentemente reduzem o deflúvio, mas com possível exceção onde as plantações podem restaurar a função hidrológica do solo em bacias degradadas pela agricultura; tipicamente reduzem o volume de sedimentos transportados nos rios quando bem desenhadas e manejadas; improvavelmente parecem reduzir inundações numa escala maior e deslizamentos profundos, mas tem sido demonstrado que reduzem deslizamentos superficiais e inundações locais; podem influenciar o clima global, mas as taxas atuais de plantações provavelmente são negligentes e, possivelmente, aumentam a precipitação local e regional em alguns ambientes.

Finalmente, Lima (2006) descreve que um aspecto importante para o entendimento das relações entre a água e as plantações com espécie arbóreas é a escala do uso da terra e, no contexto de melhores práticas de manejo florestal, a microbacia hidrográfica deve estar incorporada como unidade sistêmica da paisagem e monitoramento, a fim de integrar todos os processos envolvidos no balanço hídrico. Desta forma, com uma escolha apropriada da microbacia a ser florestada e com plantios planificados e manejados, as plantações podem ser uma parte viável e positiva da economia rural com impactos mínimos sobre os fluxos dos rios (KEENAN et al., 2006).

\section{CONCLUSÕES}

Muitos trabalhos foram realizados sobre o uso de água pelas plantações florestais em diferentes partes do mundo, e que podem servir como guia para um manejo eficiente entre os recursos hídricos e os plantios. Porém, os resultados não podem ser extrapolados e generalizados para as diferentes situações enfrentadas. No caso do Brasil, por exemplo, os principais estudos estão direcionados principalmente para Eucalyptus grandis na região sudeste, o que se justifica sendo a espécie e região de maior importância e concentração das plantações. Todavia, pouco se sabe sobre o comportamento hídrico desta espécie e de outras espécies importantes para o setor florestal em distintas regiões do país, havendo muito para avançar neste sentido.

Apesar da existência de uma vasta literatura referente ao uso da água pelas plantações florestais, muitas das polêmicas relacionadas ao tema não são elucidadas devido a que os resultados destas pesquisas não chegam ao alcance dos responsáveis pela elaboração de políticas estratégicas e sustentáveis para uma determinada região. Somente com a diminuição da separação que existe entre a ciência e a sociedade é que o conhecimento científico pode ter uma aplicação prática e os paradigmas esclarecidos.

No contexto atual de mudanças climáticas e recursos naturais cada vez mais escassos, o foco deve ser o cuidado com os recursos em todos os âmbitos e sua utilização racional. Em adição à adoção de boas práticas de manejo dos povoamentos, tam- 
bém se pode pensar em outras características, além da produtividade, no momento de selecionar uma espécie para uma determinada região com aptidão florestal, por exemplo, espécies mais eficientes no uso de água. Com a aplicação do conhecimento e da tecnologia existentes, o caminho da sustentabilidade pode ser alcançado em todos os aspectos.

\section{REFERÊNCIAS BIBLIOGRÁFICAS}

ALMEIDA, A. C. et al. Needs and opportunities for using a process-based productivity model as a practical tool in Eucalyptus plantations. Forest Ecology and Management, v. 193, p. 167-177, 2004.

ALMEIDA, A. C.; SOARES, J. . Comparação entre uso de água em plantações de Eucalyptus grandis e Floresta Ombrófila Densa (Mata Atlântica) na costa leste do Brasil. Revista Árvore, v. 27, n. 2, p. 159170, 2003.

ALMEIDA, A. C. et al. Growth and water balance of Eucalyptus grandis hybrid plantations in Brazil during a rotation for pulp production. Forest Ecology and Management, v. 251, p.10-21, 2007. ANDREASSIAN, V. Waters and forests: from historical controversy to scientific debate. Journal of Hydrology, v. 291, p. 1-27, 2004.

BENYON, R.; DOODY, T.M. Water use by tree plantations in south east south Australia. Victoria, 2004, 26 p. (CSIRO Technical Report 148).

BENYON, R. et al. Tree water use in forestry compared to other dry-land agricultural crops in the Victorian context: report prepared for the Department of Primary Industries Victoria to promote scientific knowledge in this area. Victória, 2007. 50 p. (Ensis Technical Report, 159).

BROWN, A. E. et al. A review of paired catchment studies for determining change in water yield resulting from alterations in vegetation. Journal of Hydrology, v. 310, p. 28-61, 2005.

BROWN, A. E. et al. Predicting the impact of plantation forestry on water users at local and regional scales An example for the Murrumbidgee River Basin, Australia. Forest Ecology and Management, v. 251, p. 82-93, 2007.

BRUIJNZEEL, L. A. Hydrological functions of tropical forests: not seeing the soil for the trees? Agriculture, Ecosystems and Environment, v. 104, p. 185-228, 2004.

CALDER, I. R. Water use of eucalypts - a review with special reference to South India. Agricultural
Water Management, v. 11, p. 333-342, 1986.

CALDER, I. R. Water use by forests, limits and controls. Tree Physiology, v. 18, p. 625-631, 1998.

CALDER, I. R. Forests and water - ensuring forest benefits outweigh water costs. Forest Ecology and Management, v. 251, p. 110-120, 2007.

CALDER, I. R. et al. Hacia una nueva comprensión de los bosques y el agua. Unasylva, v. 58, n. 229, p. 3-10, 2007.

CANNELL, M. G. R. Environmental impacts of forest monocultures: water use, acidification, wildlife conservation, and carbon storage. New Forests, v. 17, p. 239-262, 1999.

CÂMARA, C. D.; LIMA, W. P. Corte raso de uma plantação de Eucalyptus saligna de 50 anos: impactos sobre o balanço hídrico e a qualidade da água em uma microbacia experimental. Scientia Forestalis, v. 56, p. 41-58, 1999.

CÂMARA, C. D.; LIMA, W. P.; ZAKIA, M. J. B. Critérios e indicadores hidrológicos de monitoramento em microbacias. In: LIMA, W. P.; ZAKIA, M. J. B. (Org.). As plantações florestais e a água - implementando o conceito da microbacia hidrográfica como unidade de planejamento. São Carlos, RiMa. 2006. p. 107-140.

CARLESSO, R.; ZIMMERMMANN, F. L. Água no solo: Parâmetros para dimensionamento de sistemas de irrigação. Santa Maria: UFSM. Departamento de Engenharia Rural, 2000. 88 p.

CECCON, E.; MARTINEZ-RAMOS, M. Aspectos ambientales referentes al establecimiento de plantaciones de eucalipto de gran escala en áreas tropicales: aplicación al caso de México. Revista Interciencia, v. 24, n. 5, 1999.

CHANG, M. Forest hydrology: an introduction to water and forests. 2nd ed. United States: Taylor \& Francis. 2006. 474 p.

DYE, P.J. Response of Eucalyptus grandis trees to soil water deficits. Tree Physiology, v. 16, p. 233238, 1996.

DYE, P.; VERSFELD, D. Managing the hydrological impacts of South African plantation forests: An overview. Forest Ecology and Management, v. 251, p. 121-128, 2007.

ELLIS, T.; HATTON, T.; NUBERG, I. An ecologically optimality approach for predicting deep drainage from tree belts of alley farms in water-limited environments. Agricultural Water Management, v. 75, p. 92-116, 2005.

FARLEY, K. A.; JOBBAGY, E. G.; JACKSON, R. B. Effects of afforestation on water yield: a global synthesis with implications for policy. Global 
Change Biology, v. 11, p. 1565-1576, 2005.

HAMILTON, L. S. Forests and water - Thematic study prepared in the framework of the Global Forest Resources Assessment 2005, Roma. FAO Forestry paper, v. $155,2008.78$ p.

HATTON, T. et al. Does water efficiency vary among eucalypts in water-limited environments. Tree Physiology, v. 18, p. 529-536, 1998.

HUBER, A. J.; TRECAMAN, R. V. Eficiencia del uso del agua en plantaciones de Pinus radiata en Chile. Bosque, v. 25, n. 3, p. 33-43, 2004.

ILSTEDT, U. et al. The effect of afforestation on water infiltration in the tropics: A systematic review and meta-analysis. Forest Ecology and Management, v. 251, p. 45-51, 2007.

JACKSON, R. B. et al. Trading water for carbon with biological carbon sequestration. Science, v. 310, p. 1944- 1947, 2005.

JAROSZ, N. et al. Carbon dioxide and energy flux partitioning between the understorey and the overstorey of a maritime pine forest during a year with reduced soil water availability. Agricultural and Forest Meteorology, v. 148, p. 1508-1523, 2008.

KALLARACKAL, J.; SOMEN, C. K. Water use by Eucalyptus tereticornis stands of differing density in southern India. Tree Physiology, v. 17, 195-203, 1997.

KEENAN, R.J. et al. Plantations and Water: Plantation Impacts on Stream Flow. Science for Decision Makers. Australian Government. Department of Agriculture, Fisheries and Forestry. Bureau of Rural Sciences. 2006. 8 p. Disponível em: http://www.acera.unimelb.edu.au/materials/ brochures/SDM-PlantationsWater. Acesso em: 16 de abril 2009.

LARCHER, W. Ecofisiologia Vegetal. São Carlos: Rima. 2006. $531 \mathrm{p}$.

LELES, P.S.S. et al. Relações hídricas e crescimento de árvores de Eucalyptus camaldulensis e Eucalyptus pellita sob diferentes espaçamentos na região de cerrado. Revista Árvore, v. 22, p. 41-50, 1998.

LI, X. Y. et al. Stemflow in three shrubs and its effect on soil water enhancement in semiarid loess region of China. Agricultural and Forest Meteorology, v. 148, p. 1501-1507, 2008.

LICATA, J. A. et al. Increased water use by ponderosa pine plantations in northwestern Patagonia, Argentina compared with native forest vegetation. Forest Ecology and Management, v. 255, p. 753-764, 2008.
LIMA, W. P. Impacto ambiental do eucalipto. 2. ed. São Paulo: EDUSP, 1993. 301 p.

LIMA, W. P. Efeitos hidrológicos do manejo de plantações florestais. In: LIMA, W. P.; ZAKIA, M. J. B. (Org.). As plantações florestais e a água - implementando o conceito da microbacia hidrográfica como unidade de planejamento. São Carlos, RiMa. 2006. p. 9-28.

LIMA, W. P. et al. Promab: Histórico, Fundamentos e Conquistas. Documentos Técnicos IPEF, v. 1, n. 1,2008 .

LIMA, W. P. et al. Comparative evapotranspiration of Eucalyptus, Pine and "Cerrado" vegetation measured by the soil water balance method. IPEF International, v. 1, p. 5-11, 1990.

LIMA, W. P.; ZAKIA, M. J. B. Hidrologia de matas ciliares. IPEF, 2004. Disponível em: http://www. ipef.br/hidrologia/mataciliar.asp. Acesso em: $10 \mathrm{de}$ agosto 2011.

MCJANNET, D.L.; VERTESSY, R.A. Effects of thinning on wood production, leaf area index, transpiration and canopy interception of a plantation subject to drought. Tree Physiology, v. 21, p. 10011008, 2001.

MCJANNET, D. L.; VERTESSY, R. A.; CLIFTON, C. A. Observations of evapotranspiration in a break of slope plantation susceptible to periodic drought stress. Tree Physiology, v. 20, p. 169-177, 2000. MENDES, C. A. M.; LIMA, W. P. Análise de impactos ambientais de plantações florestais no contexto de bacias hidrográficas: princípios norteadores. In: SEMINÁRIO DE RECURSOS HÍDRICOS DA BACIA HIDROGRÁFICA DO PARAIIBA DO SUL: O EUCALIPTO E O CICLO HIDROLÓGICO, 1., 2007, Taubaté. Anais... Taubaté: Unitau, 2007. p. 263-270. Disponível em: www.agro.unitau.br/serhidro Acesso em: 04 de março 2009.

MIELKE, M. S. et al. Stomatal control of transpiration in the canopy of a clonal Eucalyptus grandis plantation. Trees, v. 13, p. 152-160, 1999.

PALLARDY, S. G. Physiology of wood plants. 3rd ed. United States: Elsevier. 2008. 454 p.

ROBERTS, S.; VERTESSY, R.; GRAYSON, R. Transpiration from Eucalyptus sieberi (L. Johnson) forests of different age. Forest Ecology and Management, v. 143, p. 153-161, 2001.

SCHRELZENMAYR, M. et al. Der Wald. Vrania Verlag: Berlim, 1981. 264 p.

SOARES, J. V.; ALMEIDA, A. C. Modeling the water balance and soil water fluxes in a fast growing Eucalyptus plantation in Brazil. Journal 
of Hydrology, v. 253, p. 130-147, 2001.

STAPE, J. L.; BINKLEY, D.; RYAN, M. G. Eucalyptus production and the supply, use and efficiency of use of water, light and nitrogen across a geographic gradient in Brazil. Forest Ecology and Management, v. 193, p. 17-31, 2004.

VANCLAY, J. K. Managing water use from forest plantations. Forest Ecology and Management, v. 257, p. 385-389, 2009.

VAN DIJK, A. I. J. M. et al. Reforestation, water availability and stream salinity: A multi-scale analysis in the Murray-Darling Basin, Australia. Forest Ecology and Management, v. 251, p. 94109, 2007.

VAN DIJK, A. I. J. M.; KEENAN, R. Planted forests and water in perspective. Forest Ecology and Management, v. 251, p. 1-9, 2007.

VERTESSY, R. A.; WATSON, F. G. R.; O'SULLIVAN, S. K. Factors determining relations between stand age and catchment water balance in mountain ash forests. Forest Ecology and Management, v. 143, p. 13-26, 2001.

VINCKE, C.; THIRY, Y. Water table is a relevant source for water uptake by a Scots pine (Pinus sylvestris L.) stand: Evidences from continuous evapotranspiration and water table monitoring. Agricultural and Forest Meteorology, v. 148, p. 1419-1432, 2008.

WALLACE, J. S. Calculating evaporation: resistance to factors. Agricultural and Forest Meteorology, v. 73, p. 353-366. 1995.

WHITEHEAD, D.; BEADLE, C. L. Physiological regulation of productivity and water use in Eucalyptus: a review. Forest Ecology and Management, v. 193, p. 113-140, 2004.

WILK, J. Local perceptions about forests and water in two tropical catchments. GeoJournal, v. 50, p. 339-347, 2000.

ZHANG, L; DAWES, W. R; WALKER, G. R. Predicting the effect of vegetation changes on catchment average water balance. Camberra: Cooperative Research Centre For Catchment Hydrology, 1999. 35 p. (Technical Report 99/12). ZIMMERMANN, B.; ELSENBEER, H.; DE MORAES, J.M. The influence of land-use changes on soil hydraulic properties: implications for runoff generation. Forest Ecology and Management, v. 222, p. 29-38, 2006. 